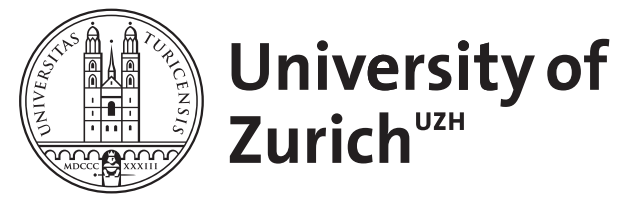

\title{
Rejoinder to Huijbregts's: Biting into evolution of language
}

\author{
Moran, Steven ; Bickel, Balthasar
}

DOI: https://doi.org/10.1093/jole/lzaa005

Posted at the Zurich Open Repository and Archive, University of Zurich ZORA URL: https://doi.org/10.5167/uzh-189233

Journal Article

Accepted Version

Originally published at:

Moran, Steven; Bickel, Balthasar (2020). Rejoinder to Huijbregts's: Biting into evolution of language. Journal of Language Evolution, 5(2):184-187.

DOI: https://doi.org/10.1093/jole/lzaa005 


\title{
Rejoinder to Huijbregts's: Biting into evolution of language
}

\author{
Steven Moran and Balthasar Bickel
}

University of Zurich

Huijbregts's commentary ${ }^{1}$ gives us the opportunity to highlight an ongoing problem in the investigation of language evolution that has hindered its research since the 19th century: the lack of engagement with empirical data. This problem stems partially from the issue of how language is defined, and consequently, how researchers engage in meaningful evolutionary investigations. First we discuss this general issue and then we will assess Huijbregts's lack of engagement with empirical data and the state-of-the art with regard to his comments on phonetics and phonology.

While there has been a long philosophical tradition in trying to extract and define what language is in its very essence (e.g., a communication tool, a type of cognitive computation, rule-governed behavior), it is clear that language is an evolved phenomenon unique to our species. Like any such phenomenon, standard evolutionary theory advises us to break the phenomenon down into its component parts and study their evolutionary trajectories and the interactions among them (Townsend et al., 2018). It is in this spirit that Hauser et al. (2002) paved the way for novel scientific approaches to the question almost twenty years ago. Most importantly, they divided language into unique and broader such components, summarized under the headers of the Faculty of Language in the Narrow Sense (FLN, core syntax) and the Faculty Language in the Broad Sense (FLB, including some of Hockett's design features but also such components as our vocal tract biomechanics). The very terminology makes clear that both dimensions belong to the faculty of language and are essential for understanding its evolution. Indeed, a full understanding of either requires in-depth empirical research on both. This is true even if one accords secondary importance to FLB. As Fitch (2017) observes, assuming that externalized communication through sound sequences is of secondary importance does not make it irrelevant for a full understanding of language's evolution.

As the title of our paper makes very clear, we do not address any FLN issues. Instead, we investigate the evolution of speech sounds due to a change in our biology, a key issue for FLB. Our orofacial morphology and the biomechanical cost of producing labiodental sounds has observably changed due to the adoption and spread of food processing technologies and agricultural practices since the Neolithic. We believe this observation and our study lays the groundwork for investigating a much bigger picture -- how did spoken language evolve and is now the way it is?

Comparative research shows that modern humans have evolved fine control of our vocal tracts, whereas extant great ape species have not. This process involved the evolutionary

\footnotetext{
${ }^{1}$ We note that some of the material in this commentary by Huijbregts was also posted as an eLetter, a non-peer reviewed comment, to the Science website:

https://science.sciencemag.org/content/363/6432/eaav3218/tab-e-letters.
} 
development of connections between our motor cortex and our speech apparatus. For example, recent work by Belyk \& Brown (2017) discusses the evolutionary development of the brain and the larynx motor cortex with an emphasis on the neural mechanisms of vocalization and the resulting phylogenetic changes to the function and structure of the human brain (in contrast to the brains of great apes). This work engages with comparative neuroscience and comparative animal communication studies. It is empirically-driven, modern research and contrasts with, for example, Huijbregts's assumptions of universal distinctive features that builds on theoretical work from the last century.

From his discussion it becomes clear that Huijbregts has phonological features in mind, and not surface-level acoustic-phonetic features. The difference is important. While there is growing evidence of how acoustic-phonetic features, i.e., spectrotemporal correlates of articulatory postures and gestures (e.g., voice onset time and vowel formant frequency) are represented in the superior temporal gyrus (see McCloy \& Lee, 2019 for recent review), studies of phonetic feature representations in the brain have often ignored how sounds pattern together phonologically in the languages under investigation. Thus, as McCloy \& Lee (2019) conclude, "the promise of phonological features as a model of speech sound representation or processing in the human brain is far from being conclusively established."

Nevertheless, there is much promising and cutting edge research going on in these areas. For example, work by Lahiri and colleagues (see Lahiri \& Reetz, 2010 for an overview) has tested hypotheses about how specific phonological contrasts are processed in specific languages. And although neuroscience is far from identifying an entire phonological feature system in neural activity, recent work shows that the Sound Patterns of English (SPE) feature set is not representative of the brain when testing the best fit between neural recordings and speech perception for consonants in English (McCloy \& Lee, 2019).

Huijbregts finds the evolution of labiodental sounds irrelevant because they do not correspond to anything on the level of phonological features. While we find surface-level sounds and phonetic features just as important for the evolution of FLB as phonological features, there is in fact good evidence for a labiodental feature.

Huijbregts builds his view on phonological features largely on SPE, but there are volumes on why SPE's features are inadequate for describing a multitude of languages and a multitude of phonological phenomena within any number of languages (see Port \& Leary, 2005, and references therein). ${ }^{2}$ Huijbregts's comments fail to engage with the decades of discussion of SPE's shortcomings and more recent developments in distinctive feature theory in general. But it isn't even clear what feature system Huijbregts has in mind. For example, in order to refute labiodental as a feature, Huijbregts uses the feature [labial] to capture natural classes of the sounds $[p, f, t, \theta, k, x]$ but this feature isn't even present in SPE. Then again, in order to account

\footnotetext{
${ }^{2}$ Hence "English" in the book's title.
} 
for the distinction between $/ \varphi /, / \beta /$ and /f/, /v/ in Ewe (Ladefoged, 1964), he points to the SPE feature [strident].

The example of [strident] is instructive. The feature has been defined and redefined in acoustic, articulatory, and perceptual terms over the decades. Which are we talking about here? Acoustic and perceptual studies do not support classifying labiodental fricatives as [strident] sounds because there is no rise in amplitude at higher frequencies (see Kim et al., 2015) and explanation and references therein). Ladefoged (1997) argues that [strident] (which he renamed [sibilant]) should be restricted to coronal sounds. Thus, non-coronal sounds, including [f] and [ $\beta$ ] are unspecified with regard to [strident] in modern features sets, including Hayes's (2009), which is well accepted and intended to have broad typological coverage. This leaves [ $f$ ] and [ $\beta$ ] non-contrastive without an additional feature, such as [labiodental], which was already explicitly proposed by Palmada (1995b) for several languages (Hall, 1997; Kim et al., 2015; see also Palmada, 1995a). Hayes (2009), pg 86, footnote 5) also argues that if [f] and [v] are classified [strident], in English we would expect 'cuff' and 'dove' to be pluralized as *[ 'k^fəz] and

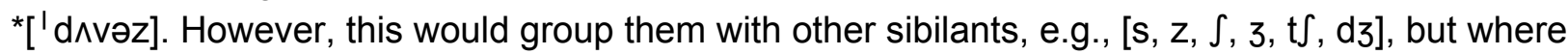
is the empirical support for such a grouping?

Adopting a [labiodental] feature (or whatever one wants to call it) solves the long standing issue of how to encode the bilabial-labiodental distinction, but empirically more research is needed to identify which spectral properties are the determinants of the perception of this place of articulation (Kim et al., 2015). This is in part due to the fact that in the phonetics literature, as we have noted with stridency, there may be little agreement on the phonetic nature of distinctive features. This should not be surprising given the fact that phonological features have been defined both in articulatory and acoustic terms (cf. Flemming, 2002), but that many sound patterns include natural classes that are acoustically similar, but that do not share an articulatory property.

Another issue with Huijbregts's position regarding distinctive features is the lack of empirical evidence that they comprise a universal set. Although distinctive features may widely be assumed to be innate, there are many challengers of the assumption of universality. For example, Mielke (2008) argues that distinctive features are properties that emerge during language acquisition. His survey of 561 languages finds that a whopping quarter of the observed phonological classes cannot be defined by any distinctive feature set (and some unnatural classes tend to be more frequent than natural ones). Instead of engaging with the empirical evidence put forth by Mielke, i.e., the fact that SPE (and all other distinctive feature sets to date) cannot capture the cross-linguistic evidence reported in the language documentation literature, Huijbregts brushes this evidence away by appealing to the ubiquity of puzzling exceptions in other fields and a liberal use of markedness concepts in the SPE tradition.

Support for an innate universal distinctive feature set comes from early language acquisition studies, which suggested an infant's ability to distinguish all phonetic contrasts (e.g., Eimas et 
al., 1971). However, findings by Kuhl \& Miller (1975) show that chinchillas can distinguish between voiceless and voiced stop stimuli. As Mielke \& Hume (2006) point out, "If chinchillas show human-like categorical perception, it seems less plausible that the same observations from infant speech perception can be attributed to innate processing abilities specific to human language." They note that Aslin \& Pisoni (1980) argue that an infant's ability to detect contrasts in voice-onset timing (often encoded as the distinctive feature [voice]) is due to constraints on the auditory system shared by mammals. Yet another reason why we should continue to investigate whether distinctive features are actually universal or part of a longer term evolutionary development.

A second issue for which Huijbregts finds our study irrelevant is the faculty that children bring to language. Indeed, from what we report about how our bite configuration changes during development, there is no doubt that pre-Neolithic children had the capacity for labiodental articulations. But if these sounds are not part of any language they might learn (because the adults' bite configuration makes their articulation extremely unlikely), this capacity is irrelevant for language. Children can also produce sneeze-like sounds and dozens of others sounds like that, but these are not commonly argued to be part of the Faculty of Language (in the broad sense) because they are simply irrelevant for language. We are not aware of any empirical evidence for a specifically linguistic capacity for labiodentals in pre-Neolithic speech. But we are aware of the very low probability that our data and models ascribe to them.

Ultimately, however, we suspect that such debates will not advance our knowledge of language evolution. One can always refine one's notion of "faculty" and "relevance", or develop further one's concepts of features and phonology. Debates of this kind have dominated linguistics for much of its recent past. It is high time, we submit, to replace such conceptual debates with empirical research on specific components of language, engaging with the best evidence we can get from a large variety of disciplines. 


\section{References}

Alan Hall, T. (1997). The Phonology of Coronals. John Benjamins Publishing.

Aslin, R. N., \& Pisoni, D. B. (1980). Some developmental processes in speech perception. In Yeni-Komshian G. H., Kavanaugh J. F., \& Ferguson C. A. (Ed.), Child phonology, Vol. 2: Perception (pp. 67-96). Academic Press.

Belyk, M., \& Brown, S. (2017). The origins of the vocal brain in humans. Neuroscience and Biobehavioral Reviews, 77, 177-193.

Eimas, P. D., Siqueland, E. R., Jusczyk, P., \& Vigorito, J. (1971). Speech perception in infants. Science, 171(3968), 303-306.

Fitch, W. T. (2017). On externalization and cognitive continuity in language evolution. Mind \& Language, 32, 597-606.

Flemming, E. S. (2002). Auditory Representations in Phonology. Routledge.

Hauser, M. D., Chomsky, N., \& Fitch, W. T. (2002). The faculty of language: what is it, who has it, and how did it evolve? Science, 298(5598), 1569-1579.

Hayes, B. (2009). Introductory Phonology. Blackwell.

Kim, H., Clements, G. N., \& Toda, M. (2015). The feature [strident]. In van der Hulst, H., Rialland, A., \& Ridouane, R. (Ed.), Features in phonology and phonetics (pp. 179-194).

Kuhl, P. K., \& Miller, J. D. (1975). Speech perception by the chinchilla: voiced-voiceless distinction in alveolar plosive consonants. Science, 190(4209), 69-72.

Ladefoged, P. (1964). A Phonetic Study of West African Languages. Cambridge University Press.

Ladefoged, P. (1997). Linguistic phonetic descriptions. In Hardcastle, W. J. \& Laver, J. (Eds.), The handbook of phonetic sciences (pp. 589-618). Blackwell.

Lahiri, A., \& Reetz, H. (2010). Distinctive features: Phonological underspecification in 
representation and processing. Journal of Phonetics, 38(1), 44-59.

McCloy, D. R., \& Lee, A. K. C. (2019). Investigating the fit between phonological feature systems and brain responses to speech using EEG. Language, Cognition and Neuroscience, 34(5), 662-676.

Mielke, J. (2008). The emergence of distinctive features. Oxford University Press.

Mielke, J., \& Hume, E. (2006). Distinctive Features. Encyclopedia of Language \& Linguistics, 2nd edition. Elsevier.

Palmada, B. (1995a). From place to continuity. In van der Hulst, H., \&. van der Weijer, A. J. (Ed.), Leiden in Last. HIL Phonology Papers 1 (pp. 299-313). Holland Academic.

Palmada, B. (1995b). En defensa de labiodental. Anuario Del Seminario de Filología Vasca Julio de Urquijo, 11-24.

Port, R. F., \& Leary, A. (2005). Against formal phonology. Language, 81(4), 927-964.

Townsend, S. W., Engesser, S., Stoll, S., Zuberbühler, K., \& Bickel, B. (2018). Compositionality in animals and humans. PLoS Biology, 16(8), e2006425. 